\title{
Prevalence of Trypanosoma lewisi in Rattus norvegicus from Belo Horizonte, State of Minas Gerais, Brazil
}

\section{Pedro Marcos Linardi ${ }^{+}$, José Ramiro Botelho}

\author{
Departamento de Parasitologia, Instituto de Ciências Biológicas, Universidade Federal de Minas Gerais, Caixa Postal 486, \\ 30161-970 Belo Horizonte, MG, Brasil
}

\begin{abstract}
From April 1984 to March 1985, a Trypanosoma lewisi prevalence of $21.7 \%$ was found in 429 Rattus norvegicus trapped in Belo Horizonte, State of Minas Gerais, Brazil. The infection rates were higher in male and young rats and could be attributed to ecological and behavioral factors. T. lewisi was observed in rats measuring between 60 and $250 \mathrm{~mm}$. Data about monthly T. lewisi infections throughout the year are presented for the first time in Brazil, with the highest prevalences observed in the warm-rainy season (October to March).
\end{abstract}

Key words: Trypanosoma lewisi - blood trypomastigotes - Rattus norvegicus - infection rates - sex-age host - seasonal periods Minas Gerais - Brazil

The trypanosomes of mammals are divided into two sections, Stercoraria and Salivaria, according to the developmental cycle in vectors (Hoare 1972). In Stercoraria, the development is completed in the faecal medium of the posterior portion of the insect and transmission is contaminative. One of the subgenera included in this section, Herpetosoma, comprises about 45 species, whose adult blood forms are morphologically indistinguishable from those of the type-species, Trypanosoma (Herpetosoma) lewisi. This species parasitizes synanthropic rodents of the genus Rattus and has rat-fleas as vectors. Although Xenopsylla cheopis, Nosopsyllus fasciatus, Ctenocephalides canis and C. felis have been incriminated as intermediate hosts (Molyneux 1969), X. cheopis is the principal vector in tropical and subtropical areas (Hoare 1972).

Although this trypanosome is a non-pathogenic blood flagellate, Guerrero et al. (1997) demonstrated that T. lewisi infection increases Toxoplasma gondii multiplication in white rats.

Studies on prevalence of T. lewisi in murine populations were mainly made at the middle of the century by Laird (1951) in New Zealand, Callero (1952) in Panama, Eyles (1952) in USA and Kartman (1954) in Hawaii. More recently, this infection has been reported from Asiatic or African countries by Linxian et al. (1994) in the People's Republic of China, Ugbomoiko (1997) in Nigeria, Laha et al. (1997) in India, and Abdel-Aal and Abou-Eisha (1997) in Egypt. Up to now, South American records include Chile (Franjola et al. 1995) and Venezuela (Herrera \& UrdanetaMorales 1997).

Here we report the prevalence of $T$. lewisi in connection with sex and host age in Rattus norvegicus and the monthly examination records for Brazil.

${ }^{+}$Corresponding author and research fellow CNPq. Fax: +55-31-3499.2970. E-mail: linardi@icb.ufmg.br Received 27 March 2001

Accepted 16 January 2002

\section{MATERIALS AND METHODS}

During a rat-flea survey for epidemiological surveillance in Belo Horizonte, State of Minas Gerais, Brazil, 429 $R$. norvegicus were trapped around dumps at the margins and surroundings of the Rio Arrudas, from April 1984 to March 1985. Rats were killed by chloroforming and blood from the tail was used to prepare the blood films later stained with Giemsa. Trypanosomes were identified after examination under a 100x objective.

Rats were separated according to sex and divided into six age-groups considering the length of the head plus body from 0 to $280 \mathrm{~mm}$, and were also classified as immatures (0 to $140 \mathrm{~mm}$ ); young matures (141 to $200 \mathrm{~mm}$ ) and adults (more than $201 \mathrm{~mm}$ ). Monthly prevalences were also determined and grouped by seasonal periods, with a dry-cool season from April to September 1984 and a warmrainy season from October 1984 to March 1985.

The chi-square analysis was used to determine the degree of association between infection and factors considered.

\section{RESULTS}

T. lewisi was observed in a total of 93 out of $429 R$. norvegicus $(21.7 \%)$. The infection rate was different in both sexes, $24.9 \%(68 / 273)$ being detected for males and $16 \%(25 / 156)$ for females. The infection rates related to length and host age are shown in Table I. The smallest rat in which T. lewisi was found measured $60 \mathrm{~mm}$ and the largest one measured $250 \mathrm{~mm}$.

The monthly prevalence and the infection rates of $T$. lewisi related to seasonal periods are shown in Table II.

\section{DISCUSSION}

The overall prevalence of rats found to be infected with $T$. lewisi in the present study $(21.7 \%)$ is higher than that for any other country except India, where a value of $82.3 \%$ was recorded (Laha et al. 1997). Other studies have recorded values of $4.6 \%$ in New Zealand (Laird 1951), 8.9\% in Nigeria (Ugbomoiko 1997), 11.4\% in Hawaii (Kartman 1954), $13.2 \%$ in both the USA (Eyles 1952) and Egypt (Abdel-Aal \& Abou-Eisha 1997), 20\% in Italy (De Carnieri 
TABLE I

Prevalence of Trypanosoma lewisi in length classes of Rattus norvegicus from Belo Horizonte, State of Minas Gerais, Brazil

\begin{tabular}{|c|c|c|c|c|c|}
\hline $\begin{array}{l}\text { Length class } \\
(\mathrm{mm})\end{array}$ & Host age & $\begin{array}{c}\text { No. } \\
\text { examined }\end{array}$ & $\begin{array}{c}\text { No. } \\
\text { infected }\end{array}$ & $\begin{array}{c}\% \\
\text { infection }\end{array}$ & $\begin{array}{c}\text { Significance between } \\
\text { classes }\end{array}$ \\
\hline 1. $0-110$ & Immature & 24 & 5 & 20.8 & \\
\hline \multirow[t]{2}{*}{ 2. $111-140$} & Immature & 94 & 27 & 28.7 & 1 and $2: p>0.05$ \\
\hline & Total & 118 & 32 & 27.1 & \\
\hline 3. $141-170$ & Young mature & 79 & 29 & 36.7 & 2 and $3: p>0.05$ \\
\hline \multirow[t]{2}{*}{ 4. $171-200$} & Young mature & 85 & 19 & 22.3 & 3 and $4: p<0.05$ \\
\hline & Total & 164 & 48 & 29.3 & \\
\hline \multirow{3}{*}{$\begin{array}{l}\text { 5. } 201-230 \\
\text { 6. } 231-260\end{array}$} & Adult & 115 & 12 & 10.4 & 4 and 5: $p<0.05$ \\
\hline & Adult & 32 & 1 & 3.1 & 5 and $6: p>0.05$ \\
\hline & Total & 147 & 13 & 8.8 & \\
\hline Total & & 429 & 93 & 21.7 & $1+2+3+4$ and $5+6: p<0.01$ \\
\hline
\end{tabular}

TABLE II

Monthly prevalence values of Trypanosoma lewisi in Rattus norvegicus from Belo Horizonte, State of Minas Gerais, Brazil, between April 1984-March 1985

\begin{tabular}{|c|c|c|c|c|}
\hline Months & Seasons & No. examined & No. infected & $\%$ infection \\
\hline Apr. 84 & Dry-cool & 21 & 3 & 14.3 \\
\hline May 84 & Dry-cool & 25 & 3 & 12 \\
\hline June 84 & Dry-cool & 26 & 1 & 3.8 \\
\hline July 84 & Dry-cool & 24 & 4 & 16.7 \\
\hline Aug. 84 & Dry-cool & 28 & 6 & 21.4 \\
\hline \multirow[t]{2}{*}{ Sept. 84} & Dry-cool & 40 & 9 & 22.5 \\
\hline & Total & 164 & 26 & 15.8 \\
\hline Oct. 84 & Warm-rainy & 54 & 26 & 48.1 \\
\hline Nov. 84 & Warm-rainy & 79 & 31 & 39.2 \\
\hline Dec. 84 & Warm-rainy & 29 & 6 & 20.7 \\
\hline Jan. 85 & Warm-rainy & 22 & 4 & 18.2 \\
\hline Feb. 85 & Warm-rainy & 28 & - & - \\
\hline \multirow[t]{2}{*}{ Mar. 85} & Warm-rainy & 53 & - & - \\
\hline & Total & 265 & 67 & 25.3 \\
\hline Total & & 429 & 93 & 21.7 \\
\hline
\end{tabular}

\& Castellino 1964) and $21.3 \%$ in Venezuela (Herrera \& Urdaneta-Morales 1997). Unlike in the studies of Franjola et al. (1995) and Ugbomoiko (1997) there was a significant difference $(\mathrm{p}<0.05)$ between the infection rates in males $(24.9 \%)$ and females (16\%). These higher prevalences could be attributed to ecological and behavioral factors. Male rats have larger home ranges, show territorial behavior and are significantly more infested by $X$. cheopis than females (Linardi et al. 1985a), increasing their chances of being infected by $T$. lewisi infections.

Different age-related rates of infection have been recorded worldwide. Although Franjola et al. (1995) found no significant differences among age groups and Ugbomoiko (1997) observed higher values in adult rats, in our study the prevalence of infection in young animals $(29.3 \%)$ was similar to that of immatures $(27.1 \%)$ and more than three times higher that that recorded for adults $(8.8 \%)$.
These differences are highly significant (Table I) and agree with the results of Eyles (1952) and Kartman (1954).

The infection rates gradually increased with total body length in animals measuring $60-170 \mathrm{~mm}$ and declined thereafter. The highest rates were found in young animals (141$170 \mathrm{~mm}$ ) and immatures (111-140 mm). Significant differences were found between the infection rates of length classes $3(141-170 \mathrm{~mm})$ and $4(171-200 \mathrm{~mm})$ as well as between classes 4 and 5 (201-230 mm).

The profile of infection in T. lewisi is well known (Albright \& Albright 1991). After a rapid multiplication for 10 days, the trypanosomes stop growing and infection stabilizes for several weeks, after which the parasites suddenly disappear from the blood and the rat develops a solid immunity against re-infection. The trick used by $T$. lewisi to minimize the effects of the immune responses of the host is known as mimicry. Initially the parasites coat 
their surfaces with ablastin, a host protein later identified as immunoglobulin $\mathrm{E}$, that prevents the trypanosomes from dividing and multiplying. After several weeks, the host produces an IgM antibody that recognizes this complex on the parasite's surface and leads to the activation of the complement system resulting in rapid lysis of the trypanosomes in the blood. For this reason blood smears from adult rats show fewer trypanosomes than those from young or immature animals. Since norway rats attain sexual maturity at 75 days and only $5 \%$ of the population survives 12 months (Davis 1948), the animals probably become infected before or during their first mating. Use of hemoculture rather than examination of blood films would show infections in many rats, mainly adults, that would otherwise be considered negative.

Trypanosomes were found throughout the year except in February and March (Table II). Rats presented significantly higher prevalences of infection $(p<0.05)$ in the warm, rainy season (October to March) than in the cool, dry period (April to September). The highest values, recorded in October $(48.1 \%)$ and November (39.2\%) coincide with highest levels of infestation by X. cheopis in the municipality (Linardi et al. 1985a,b). Infection rates increased from June to October and subsequently decreased.

Infection rates of T. lewisi in Brazilian commensal rats are presented for the first time. Although this study provided data from only a single year, they show that infection rates are influenced by climatic conditions that affect the size of flea populations (Bahmanyar \& Cavanaugh 1976, Gratz \& Brown 1983, Linardi et al. 1985b). Guerrero et al. (1997) and Arrea et al. (1998) reported that under experimental conditions $T$. lewisi increased $T$. gondii multiplication in white rats, changing the susceptibility of the host to the parasite. This observation deserves greater attention than it received when published, since (a) $T$. gondii-infected rats are considered important in the epidemiology of toxoplasmosis because they can serve as reservoirs of infection for pigs, dogs and cats (Dubey \& Frenkel 1998); (b) a high prevalence of $T$. gondii was found recently in R. norvegicus on farms in England, suggesting that Toxoplasma infections can be perpetuated in wild rodent populations without the presence of cats (Webster 1994); (c) T. gondii infection may enhance the likelihood of infected rats being predated by cats (Webster 1994, Berdoy et al. 1995a,b). Since both T. lewisi and T. gondii occur naturally in wild rats, it is possible that infections by the former could increase the number of cysts in the brain, making these rodents important sources of Toxoplasma infection for cats (Arrea et al. 1998). Thus, if increasing levels of infestation of rats by X. cheopis favor T. lewisi transmission, which in turn promotes the spread of $T$. gondii, control measures against rat toxoplasmosis should be considered. The degree to which peaks in flea population are linked to higher prevalences of $T$. gondii in rats needs to be elucidated, to determine whether flea control might result in control of rat toxoplasmosis.

\section{REFERENCES}

Abdel-Aal AA, Abou-Eisha AM 1997. The role of rats as reservoir of some internal parasites with possible public health implications in the Suez Canal area. Assiut Vet Med J 37: 174-185.

Albright JW, Albright JF 1991. Rodent trypanosomes: their conflict with the immune system of the host. Parasitol Today 7: 137-140.

Arrea GC, Carmona MC, Bermúdez OMG, Abrahams E 1998. Effect of Trypanosoma lewisi (Kinetoplastida: Trypanosomatidae) on the infection of white rats with Toxoplasma gondii (Eucoccidia: Sarcocystidae) oocysts. Rev Biol Trop 46: 1121-1123.

Bahmanyar M, Cavanaugh DC 1976. Plague Manual, WHO, Geneva, 76 pp.

Berdoy M, Webster JP, MacDonald DW 1995a. Parasite-altered behaviour: is the effect of Toxoplasma gondii on Rattus norvegicus specific? Parasitology 111: 403-409.

Berdoy M, Webster JP, MacDonald DW 1995b. The manipulation of rat behaviour by Toxoplasma gondii. Mammalia 59: 605-613.

Calero C 1952. Incidence of Trypanosoma lewisi, Sarcocystis muris, species of Spirochaeta and microfilarial larvae in rats in Panama city and suburbs. J Parasitol 38: 369.

Davis DE 1948. The survival of wild brown rats on a Maryland farm. Ecologia 29: 437-448.

De Carnieri I, Castellino S 1964. Trypanosoma lewisi in un allevamento lombardo di ratti albini. Parassitologia 6: 95.

Dubey JP, Frenkel JK 1998. Toxoplasmosis of rats: a review, with considerations of their value as an animal model and their possible role in epidemiology. Vet Parasitol 77: 1-32.

Eyles DE 1952. Incidence of Trypanosoma lewisi and Hepatozoon muris in the norway rat. J Parasitol 38: 222-225.

Franjola R, Soto G, Montefusco A 1995. Prevalencia de infección por protozoos en roedores sinantrópicos de la ciudad de Valdivia, Chile. Bol Chil Parasitol 50: 66-72.

Gratz NG, Brown AWA 1983. XII. Fleas - Biology and Control, WHO unpublished document, WHO/VBC/ 83.874, $46 \mathrm{pp}$.

Guerrero DM, Chinchilla M, Abrahams E 1997. Increasing of Toxoplasma gondii (Coccidia: Sarcocystidae) infections by Trypanosoma lewisi (Kinetoplastida, Trypanosomatidae) in white rats. Rev Biol Trop 45: 877-882.

Herrera L, Urdaneta-Morales S 1997. Synanthropic rodent reservoirs of Trypanosoma (Schizotrypanum) cruzi in the valley of Caracas, Venezuela. Rev Inst Med Trop São Paulo 39: 279-282.

Hoare CA 1972. The Trypanosomes of Mammals. A Zoological Monograph, Blackwell, Oxford, 749 pp.

Kartman L 1954. Observations on Trypanosoma lewisi and Grahamella sp. in the blood of rats from the Hamakua District, Island of Hawaii. J Parasitol 40: 571-579.

Laha R, Hemaprasanth H, Bhatta-Charya D 1997. Observations on prevalence of Trypanosoma lewisi infection in wild rats and a trial on its adaptation in unnatural host. $J$ Parasitol Appl Anim Biol 6: 5-8.

Laird M 1951. Blood parasites of mammals in New Zealand. Zool Pub Victoria U College 9: 1-14.

Linardi PM, Botelho JR, Cunha H C 1985a. Ectoparasitos de roedores da região urbana de Belo Horizonte, MG. II. Oscilações dos índices de infestação em Rattus norvegicus norvegicus. Mem Inst Oswaldo Cruz 80: 227-232.

Linardi PM, Botelho J R, Cunha HC 1985b. Ectoparasitos de roedores da região urbana de Belo Horizonte, MG. III. Índices pulicidianos, anoplurianos e acarianos em Rattus norvegicus norvegicus. Mem Inst Oswaldo Cruz 80: 277284.

Linxian H, Wenchuan Y, Wenfeng P, Yuguang L 1994. A survey on the parasitic protozoa of rodents from Xiamen Offujian province and Tacheng of Xinjiang Autonomous Region, 
China. Wuyi Sc J 12c: 144-148.

Molyneux DH 1969. Intracellular stages of Trypanosoma lewisi in fleas and attempts to find such stages in other trypanosome species. Parasitology 59: 737-744.

Ugbomoiko US 1997. Factors affecting the prevalence of pro- tozoan parasites of small mammals in southern Nigeria. Parasitica 53: 5-13.

Webster JP 1994. Prevalence and transmission of Toxoplasma gondii in wild brown rats, Rattus norvegicus. Parasitology 108: 407-411. 